\title{
Priority of stimulating creative work in innovation management in the stage of globalization
}

\author{
Svitlana Luchyk $^{1, *}$, Maryna Semykina ${ }^{2}$, Liudmyla Zapirchenko², Vasil Luchyk ${ }^{3}$, and Anna \\ Semykina ${ }^{4}$ \\ ${ }^{1}$ Chernivtsi Institute of Trade and Economics of Kyiv National University of Trade and Economics, \\ Department of Accounting and Taxation, Tsentralna Square 7, 58002, Chernivtsi, Ukraine \\ ${ }^{2}$ Central Ukrainian National Technical University, Faculty of Economics and Management, Prospekt \\ Universytetskyi 8, 25006, Kropyvnytskyi, Ukraine
}

\begin{abstract}
${ }^{3}$ NRZVO "Kamyanets-Podilsky State Institute", Department of Economic Cybernetics, Information and Socio-Cultural Activities, Street Pet 13, 32300, Kamyanets-Podilsky, Khmelnytsky region, Ukraine
\end{abstract}

${ }^{4}$ Odessa National University of Economics, Faculty of Economics and Enterprise Management, Preobrazhenskaya Street 8, 65082, Odessa, Ukraine

\begin{abstract}
Research background: It is substantiated that outdated motivational management in practice hampers the tasks of accelerated innovative development of domestic enterprises. This leads to the destruction of motives for the development of innovations, the spread of poverty among workers, in particular among developers of new ideas and innovations.

Purpose of the article: The article is devoted to the problems of modeling the process of motivational regulation of innovative activity of employees at the enterprise.

Methods: Our conceptual provisions based on analysis and generalization of data of statistics of economic activity of innovatively active enterprises of Ukraine. Practical experience of personnel management based on motivational management, results of sociological surveys of personnel and involvement of experts' conclusions the level of economic activity of staff and creativity in work.

Findings \& Value added: The proposed model of motivational regulation of innovation activity of employees is based on the mandatory identification and consideration of priority factors that enhance the incentive effect of remuneration for the creative component of work, increase innovation activity of staff and enterprises in general, increase its profitability, and competitiveness. The peculiarity of the presented model is its flexibility in the choice of motivational regulators depending on the goals of the enterprise, the presence of a block of choice of motivational priorities in regulating innovation, the possibility of adjusting its effectiveness taking
\end{abstract}

\footnotetext{
${ }^{*}$ Corresponding author: luchyksvitlana@gmail.com
} 
into account the efficiency of innovation in the enterprise and the internal and external environment.

Keywords: creative work; innovation management; globalization; motivational regulation; motivational priorities

JEL Classification: $C 51 ; F 66 ; J 01 ; M 54 ; O 30$

\section{Introduction}

World experience shows that those countries and corporations are doomed to lag behind, where creative abilities of employees, their development, creative contribution to the development of innovations are not properly valued. Ukraine can serve as a negative example in this sense. Among many objective and subjective reasons that threaten innovation processes in Ukrainian, a special place is occupied by the weakness and inefficiency of stimulating work, especially creative work associated with the development of new solutions, ideas and technologies. The contradiction between the tasks of accelerated innovation development and the presence of outdated motivational management in practice is exacerbated. This leads to a weakening of the role of motivational regulators in the field of labor, the destruction of motives for the development of innovations, the spread of poverty among workers, in particular among developers of new ideas and innovations. The unresolved problem of adequate stimulation of creative content creates obstacles in innovation management. Therefore, the urgent task at the stage of global change is the scientific search for opportunities to improve innovation management based on creating new motivational mechanisms focused on priority stimulation of creative content. The solution of this problem significantly affects the opportunities to intensify the innovative development of enterprises, increase their profitability, competitiveness, competitive position of the country in the context of global changes.

\section{Methodology}

Progressive shifts in the development of human civilization have always been closely linked with the manifestation of human creativity and the available incentives for work. This is evidenced by the history of inventions, creation and improvement of tools, new equipment, new materials, technologies, development of motivational theories, innovation management.

Scientific opinion emphasizes that international competition is increasingly dominated by those countries, corporations, enterprises that have learned to successfully manage innovation, relying primarily on the intelligence and creativity of people, the search for acceptable incentives to motivate creative work, which is associated development of new ideas and technologies. Henk W. Volberda et al. (2013) convincingly claim that management innovation explains a substantial degree of the variance of innovation performance of firms. More active stimulation of management innovation and its leverage of technological innovation will be crucial to improve the competitiveness of firms. Rick M.A. Hollen et al. (2013) extended management innovation theory by conceptualizing management innovation in an inter-organizational context. In the context of processes of getting knowledge, innovations are considered by Pierre Barbaroux et al. (2016). They provide tools for working with open innovations and user innovations. This improves the relationship between companies and creative workers, ensures their effective use. Francesco Schiavone (2021) complements innovation management by stating that although all innovator users are interested in developing innovation, not all of them have the same qualities, skills and characteristics. User innovation complements manufacturer innovation. Commercialization 
of user-generated innovations can be complex and sometimes they end up in a corner due to a lack of knowledge on how to share and sell it to the world.

At the same time, among many scientific approaches to the interpretation of innovations in science there is a consideration of innovations as a special subject of labor activity of creative, innovative content (Kolot, 2007). The term "innovative work" appears. In its interpretation, we believe that this is a consciously appropriate activity based on scientific and technological progress, aimed at creating new products, services, organizational forms and other new consumer values, their implementation, use, commercialization in various fields to obtain a beneficial effect (economic, social, environmental and others) and meeting social needs (Semykina and Paseka, 2012).

Analysis of scientific thought suggests that innovation management is considered by scientists in many ways, at different economic levels, mainly in the sense of applying a set of financial, economic, motivational, organizational, legal, socio-psychological means, methods and tools to influence innovation (countries, organizations, enterprises) in order to improve its effectiveness. In foreign publications, scientists pay much attention to the consideration of innovative work and the need to stimulate it for the development of companies, increasing their competitiveness. For example, Muhammad Jamshed Khan et al. (2012) highlight the concept of "innovative work behaviour", which is considered a dynamic and multifaceted phenomenon that necessarily encompasses creativity. To gain a competitive advantage in the current market, company managers set tasks aimed at designing new ideas. Scientists Hun Whee Lee et al. (2019) argue that active employee behavior in the workplace, or proactivity, is vital for innovative change. Management's encouragement of such active employee behavior will stimulate group innovation. Justina Naujokaitiene et al. (2015) propose to increase work creativity through technological training. The integration of technological training in the competence of employees is carried out with the support of the company's management. Employees benefit by receiving higher salaries, better working conditions, satisfaction of attention given by managers, and the feeling that their work is meaningful and contributes to the organization's operations, whereas the organization benefits as its employees are more committed to the organization and work harder and more effectively.

It is extremely important for companies to encourage employees to have leadership qualities. Todd J. Mourer and Manuel London (2015) believe that employees must grow creatively to a leader, and the organization must provide a structure of support and rewards for the development of innovative leaders. Korean researchers Hai Kyong Kim et al. (2019) share a special style of training innovative leaders, who recommend stimulating creative, creative abilities and vocal behavior of employees, which increases collective energy and creativity. Also interesting are the facts cited by Alex Bell et al. (2018). In particular, children from high-income (top 1\%) families are 10 times as likely to become inventors as those from below-median income families. Children whose families move to a high-innovation area when they are young are more likely to become inventors.

Ukraine is also one of the countries that declare the importance of innovation to solve the country's socio-economic problems. However, according to experts, in 2019-2020, the effectiveness of innovation in Ukraine decreased by all indices (Pisarenko et al., 2020), which generally indicates the weakness of innovation management in the country and unfavorable prospects for increasing the competitiveness of economic entities. This situation is primarily due to the chronic phenomenon of reducing the cost of research, development, education as a percentage of GDP, which negatively affects the quality of human capital and the ability to stimulate innovation in employees. According to the State Statistics Service of Ukraine, in 2019 only $13.8 \%$ of industrial enterprises were engaged in innovation activities (against $15.6 \%$ in 2018), which is several times less than in the EU countries. 
We share the views of scientists (Lisogor,2016; Makarova, 2015), who believe that improving innovation management should take into account global transformations in the content of labor, the functioning of labor markets. In the conditions of formation of a new economy based on knowledge and innovations, the latest trends in the structure of employment are unfolding in the world - rapid growth of the share of workers engaged mainly in intellectual work of creative content, as emphasized in the works of Libanova et al. (2016). This is especially characteristic of developed market economies. For example, in the United States (according to various experts) from the middle of the twentieth century to the beginning of the XXI century. the share of innovative labor increased from $36 \%$ to $60 \%$, the number of engineers increased 4 times, scientists - more than 5 times, intellectual labor (socalled "white collar workers") exceeded $70 \%$ of the working population, they account for more than $80 \%$ of the payroll (Semykina and Paseka, 2012). It is necessary to pay attention to the fact that the greatest successes in economic development and improvement of quality of life are achieved by those developed countries of market economy where the best conditions for innovative activity of enterprise personnel are created, where creativity in work is stimulated, especially in science, invention and innovation. At the same time, a significant share of national income and income of enterprises is provided by labor of innovative content, ie labor activity with elements of creativity.

Despite the work done, it is fair to emphasize that in the modern scientific literature there is still a lack of work focusing on the economic benefits of innovative enterprises from stimulating creative content, the feasibility of revising policies to stimulate creative work in the context of improving innovation management.

\section{Results and Discussions}

In the process of modelling we proceed from the conclusions and ideas, that scientific and technological progress, global transformations in employment, the content of labor activity have led to the fact that in the composition of labor along with the regulated (reproductive) part there is a creative (innovative) component. Analysis of the results of economic activity of Ukrainian enterprises shows that their innovative development, income from the development and implementation of innovations, sales of innovative products is becoming increasingly dependent on the ability of staff to be creative, active in developing new ideas and their implementation. In turn, this requires the employer to pay more attention to the category of employees who can work fruitfully on innovative projects. This requires appropriate incentives, effective motivational regulation in the interests of intensifying the innovative activities of the enterprise, increasing the income of the enterprise by meeting the demand for products (services) with improved characteristics through innovation. The results of a survey of experts at 14 innovative enterprises in Kirovohrad, Cherkasy, Kyiv, Khmelnytsky regions (2017-2019) showed that the nature of such incentives should be related to the priority motives of people involved in innovators (innovators):

1. Involvement to a useful business, on which the prospects of the enterprise depend, in particular its economic condition.

2. Obtaining material satisfaction.

3. Realization of interest in the work of creative content, recognition of its role and importance.

Due to this, appealing to the creative component of work, we take as an axiom the provision of three groups of reasons that motivate innovative activities of staff: the first - a group of social motives (awareness of the need to be useful to society), the second group obtaining material benefits for themselves and their family (earnings to meet current material and spiritual needs), the third - to meet the needs of creative self-realization. The intention to reconcile the motivation of the creative component with work leads to the need to consider 
the labor process as a sequence of actions aimed at transforming a particular resource, the result of which is a certain product of production, consumer qualities of which acquire a certain value in the market. The joint implementation of the regulated and creative component in labor process will be considered by us as necessarily stimulated: the regulated component of labor - wages (basic wages), the creative component of labor - remuneration (additional wages). The latter, by its motivating influence, intensifies labor activity, which leads to consequences: the motives of the first group of reasons, which have just been mentioned, contribute to the change in the consumer qualities of the product of production; motives of the third group - transformation of the used resource; motives of the second group - change of reaction of the worker to the involved stimulus.

According to the ideas about the labor process, which we adhere to, we believe that the change of material incentive $\mathrm{z}$ (fundamental salary, $\mathrm{UAH}$ ) to the amount of remuneration $\nabla \mathrm{z}$ (additional salary, UAH) leads to the following changes:

- under the influence of the creative component of labor is the transformation of used with intensity $\alpha$ (units of product per unit of resource) resource s (units of resource) on its transformation with intensity $\nabla \alpha$, i.e. according to regulations of the result of labor process is production in volume $(\alpha+\nabla \alpha) \cdot \mathrm{s} \cdot\left(1-\mathrm{e}^{-\mathrm{b} \cdot(\mathrm{z}+\nabla \mathrm{z})}\right)$, where the difference is the motivational impact on labor actions of the employee - at zero value of $z+\nabla z$ the impact is zero, with increasing $z+\nabla z$ the impact increases, approaching 1 (its maximum of possible value);

- consumer qualities of manufactured products change from $\beta$ (UAH per unit of output) to $\beta+\nabla \beta$ (UAH per unit of output), i.e. sales of manufactured products make it possible to obtain income of $(\beta+\nabla \beta) \cdot s \cdot\left(1-\mathrm{e}^{-\mathrm{b} \cdot(\mathrm{z}+\nabla \mathrm{z})}\right) \cdot(\beta+\nabla \beta)$;

- the income of the enterprise changes depending on stimulation of the development of an innovative component of human capital and creativity; comparison of income in the options of stimulating the creative component of labor and the absence of such allows to obtain an equation (Their difference - $\nabla D$ associated with the concept of profitability D from stimulating the creative component of labor), which can be used later in analyzing the benefits of stimulating creative activity variant of the absence of such $-\nabla D=(\alpha+\nabla \alpha) \cdot s \cdot\left(1-\mathrm{e}^{-\mathrm{b} \cdot(\mathrm{z}+\nabla \mathrm{z})}\right) \cdot(\beta+\nabla \beta)-\alpha \cdot \mathrm{s} \cdot\left(1-\mathrm{e}^{-\mathrm{b} \cdot \mathrm{z}}\right) \cdot \beta-\nabla \mathrm{z}$.

- The analysis of the obtained equation in the boundary representation (after division by $\nabla_{\mathrm{z}}$ and direction $\nabla_{\mathrm{z} \rightarrow 0}$ ) will be carried out on three characteristic variants of the organization of labor activity:

- the first option, according to which the stimulation of the creative component affects the change in the transformation of the resource into a finished product: in this case, after proper transformations, we are dealing with two profitability functions - if $\alpha=$ $\mathrm{c}$, then $\mathrm{D}=\mathrm{D}_{0}-\mathrm{z}$; if $\alpha=\mathrm{c} \cdot \mathrm{z}$, then $\mathrm{D}=\mathrm{D}_{0}+(\mathrm{c}-1) \mathrm{z}-\mathrm{c}\left(1-\mathrm{e}^{-\mathrm{b} \cdot \mathrm{z}}\right) / \mathrm{b}$;

- the second option, in which the stimulation of the creative component affects the change in consumer qualities of products: in this case, after the transformation of the same expression, we also get two profitability functions, similar to the previous version - if $\beta=c$, then $D=D_{0}-z$; if $\beta=c \cdot z$, then $D=D_{0}+(c-1) z-c\left(1-e^{-b \cdot z}\right) / b$;

- the third option, according to which the stimulation affects only the motivational effect, i.e. $z+\nabla z$ changes $b$ to $b+\nabla b: D=D_{0}-z-\alpha \cdot \beta \cdot s \cdot z \cdot e^{-b \cdot z} / b+\alpha \cdot \beta \cdot s \cdot\left(1-e^{-b \cdot z}\right) / b^{2}$. Other options (combined) are not considered due to the lack of possibility to reduce them to a form acceptable for analysis.

So, we are dealing with several expressions:

$$
\begin{gathered}
\mathrm{D}=\mathrm{D}_{0}-\mathrm{z} \text { in case when } \alpha=\mathrm{c}(\text { as } \beta=\mathrm{c}) \\
\mathrm{D}=\mathrm{D}_{0}+(\mathrm{c}-1) \mathrm{z}-\mathrm{c}\left(1-\mathrm{e}^{-\mathrm{b} \cdot \mathrm{z}}\right) / \mathrm{b} \text { in case when } \alpha=\mathrm{c} \cdot \mathrm{z}(\text { as } \beta=\mathrm{c} \cdot \mathrm{z})
\end{gathered}
$$




$$
D=D_{0}-z-\alpha \cdot \beta \cdot s \cdot z \cdot e^{-b \cdot z} / b+\alpha \cdot \beta \cdot s \cdot\left(1-e^{-b \cdot z}\right) / b^{2} \text { in case of change } z \text { to } b .
$$

Regarding labor activity, these equations in a generalized form describe the profitability $D$, the value of which is affected by: the initial (starting) value of profitability $\left(\mathrm{D}_{0}\right)$, the value of the wage level together with the value of remuneration $(\mathrm{z})$, the base level of resource used (s) ), the parameters of "sensitivity" to the transformation of the resource into the finished product $(\alpha)$, to changes in the consumer properties of the product $(\beta)$, to the reaction to the encouragement of creative activity (b). Note that in the case when the reward $z$ does not apply to the parameters $\alpha$ and $\beta$ (they remain constant $-\alpha=\mathrm{c}$ or $\beta=\mathrm{c}$ ), then with increasing remuneration, the profitability decreases. In this case, increasing the initial level of profitability $\mathrm{D}_{0}$ to level $2 \cdot \mathrm{D}_{0}$ doubles the range of change $\mathrm{z}$, at which the profitability remains positive, decreasing to the level of $1 / 2 \mathrm{D}_{0}$ - halves it.

If the reward $\mathrm{z}$ affects the parameters $\alpha$ and $\beta$ (they change in proportion to its value $-\alpha=$ $\mathrm{c} \cdot \mathrm{z}$ or $\beta=\mathrm{c} \cdot \mathrm{z}$ ), then with increasing reward the profitability decreases, and after reaching a certain minimum level begins to increase intensively.

In the case when the reward $\mathrm{z}$ affects the employee's reaction to the encouragement of creative activity, we observe a change in the trend from increasing profitability $\mathrm{D}$ (decreasing $b$ to $1 / 2 b$ ) to decreasing (increasing $b$ to $2 b$ ).

Thus, much depends on specific employee with the inherent needs and aspirations for creativity, processed by him in the process of labor resource, the technologies used by him, the current system of incentives for regulated and creative work. When the reward is a factor influencing not only the individual components of labor activity, which are analyzed above, but also the combined action (actions to transform the resource into a finished product, consumer qualities of the finished product, and the motives for creativity) in general, the possible dynamics of profitability is not possible. The same is limited to the remarks that are the result of the observations illustrated above.

The simulation results show that profitability of an innovatively active enterprise is quite sensitive to the manifestation of creativity and active innovative behavior of a particular employee (innovation developer). The employee, in turn, is sensitive or not sensitive enough to stimulate creative work (as a rule, the city has this when the available incentive does not meet his needs or spent labor and creative efforts). In general, the profitability of the enterprise (D) depends on the value of remuneration $\mathrm{z}$ for the manifestation of innovative activity and creativity in work, the basic level of the processed resource s, parameters characterizing the method of transforming the resource into a finished product $\alpha$, consumer properties $\beta$, employee response to creative stimulation $b$, which collectively determine the different results of work, but so that it may be: not sensitive to remuneration; sensitive, and one that helps to increase profitability or, conversely, reduce profitability.

This not only proves the importance and profitability of priority stimulation of creative work for an innovative enterprise, but also emphasizes the need to ensure the flexibility of such incentives to achieve innovative goals through greater creative activity of employees in the development of innovations and their implementation. Thus, in the interests of better management of innovations at Ukrainian enterprises and increase their profitability, it is necessary to create an effective motivational mechanism focused on activating the creative component of labor. The operation of such a mechanism should be based on the mandatory identification and consideration of priority motivational factors that enhance the incentive effect of remuneration for the creative component of work, increase innovation activity of staff and enterprises in general, increase its profitability and competitiveness.

To optimize the motivational regulators of innovation activity of employees, we propose to take into account in the process of building a motivational mechanism:

1. Priority needs of staff; priority goals and needs of an innovative enterprise.

2. Individual assessment of the results of work, including work of reproductive (regulated) and work with elements of creativity (innovative). 
3. Selected motivational priorities in regulating the innovative activity of staff in favor of stimulating the creative component of work.

4. The efficiency of innovative work recorded by experts, in particular economic, social, scientific and technical, ecological.

To the most important incentives (factors of activation of creative work) we suggest to include: economic incentives (basic and additional wages), which provide for the growth of income from the joint implementation of the regulated and creative components of labor; social incentives - compensation (social) package in the form of an individualized set of social services, which to some extent compensates for the spent intellectual and creative efforts of a particular employee (full or partial reimbursement of food, training, second education, competence development, rehabilitation, travel, etc.); moral and psychological incentives (public announcement of gratitude, presentation to the honorary title, etc.), which certify the recognition of creative achievements. Note that the possibility of choosing and improving motivational regulators of labor behavior (factors, means, and tools of influence) always exist in the enterprise and this should be taken into account when creating an adequate motivational mechanism required by its innovative activities.

The formulated conceptual provisions are illustrated in the form of the scheme of the motivational mechanism of providing priority stimulation of work of creative maintenance in figure 1.

The difference between the proposed motivational mechanism from those known in the literature is as follows:

1. The purpose and functions of the proposed mechanism are subject to the objectives of improving innovation management on the basis of priority incentives to stimulate the work of creative content.

2. The motivational mechanism provides flexibility, as required by the established economic and mathematical models (1-3). Flexibility should be provided by the choice of motivational regulators (levers and factors of influence) depending on the goals of the enterprise, the priority of needs and motives of staff, assessment of the achieved effectiveness of regulating innovation activity of employees in the interests of enterprise income growth. Flexibility of motivational regulators is extremely important at different stages and in different situations of enterprise development, especially in times of crisis, limited financial resources, in case of changing market conditions, revision of innovation goals, the need to strengthen innovation activity of specific, most valuable employees influencing the success of the innovation project in the short and long term.

3. The choice of motivational priorities in the regulation of labor behavior should be based on certain dependencies of the company's profitability from stimulating creativity at work, the amount of remuneration for innovative activity and creativity at work, its adequacy to current staff needs (1-3). In this regard, the formation of individualized compensation packages depending on the increase in the creative component of work, the current needs of innovation developers, their contribution to innovation development and the effect (economic, social, environmental, moral, technical and technological). The motivational impact of an individualized compensation package depends on the significance of its content for a particular employee. Therefore, its formation should meet the economic and social needs of developers, take into account age, marital status, health, creative inclinations, the need to stimulate behavior focused on creative achievement, professional growth, the importance of actual and expected contribution of a particular employee to innovation.

4. The scheme of the motivational mechanism (Fig. 1) laid the possibility of adjusting its effectiveness taking into account the economic condition of the enterprise, its 
profitability, efficiency of regulation of innovative work at the enterprise, changes in internal and external environment. This feature of the model is very important under the terms of dynamic demands, crisis phenomena, rapid changes in external economic, political, competitive, technical and technological, environmental and climatic conditions of enterprises, to which it is necessary to adapt as quickly as possible without losing staff, the most competent, capable and talented in terms of innovation).

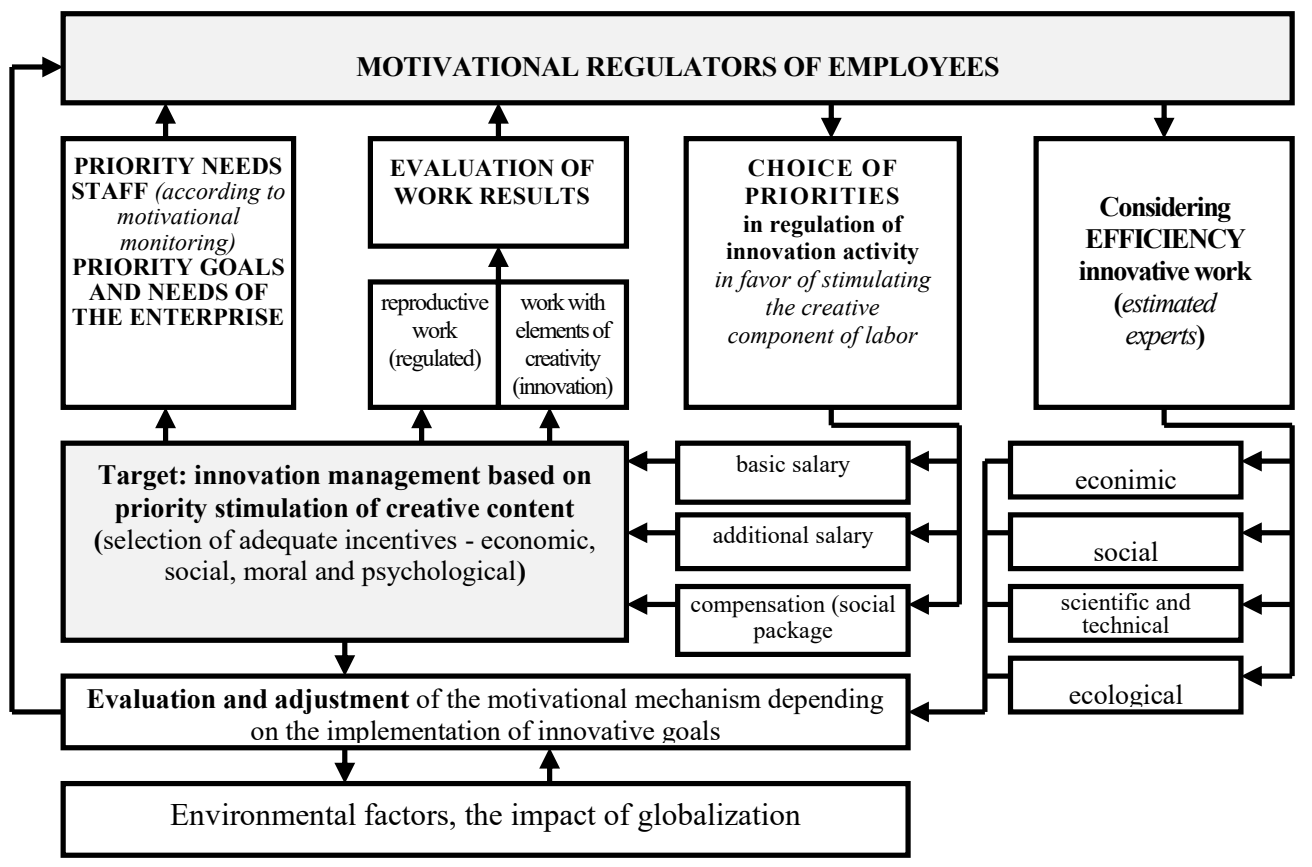

Figure 1. Conceptual scheme of the motivational mechanism of providing priority stimulation of work of creative maintenance in the context of improvement of management of innovations *

Source: Suggested by the authors

It should be borne in mind that the functioning of the proposed motivational mechanism is perceived by us as a dynamic process that reflects the close interaction of profitability of the enterprise and the manifestation of creative activity of staff, confirmed by economic and mathematical models $(1,2,3)$. Motivational regulators today and in the future can be a set of various economic, social and moral and psychological incentives important for the creativity of employees: favorable working conditions, decent wages, which allows to meet the current needs of reproduction and development of highly skilled labor, structuring work and responsibilities, opportunities for social and business contacts, creativity, providing educational and professional development with the participation of the enterprise, encouraging self-improvement, recognition of labor and creative achievements, stimulating innovative staff activity, career opportunities, diversity and content of work, positive corporate culture, interesting and yield. the opportunity to show independence in work, choose a flexible mode of work, use the benefits of remote employment (if possible), real recognition of the role of their creative achievements for the company using methods of moral and psychological motivation (without reducing the role of material motivation), social support of the enterprise in solving problems of quality food, affordable housing, rehabilitation, providing access to various sources of information also play an important role for creative people. In turn, the organization of work and conditions of personnel 
development at most enterprises of Ukraine need to be significantly changed, taking into account the latest trends in the labor market: continuous professional development, mobility, flexibility, adaptability, remoteness, innovation, manufacturability, readiness to respond to market demand. not only the properties of goods, products, services, but also service, quality, speed of service. Thus, the choice of motivational priorities in the regulation of labor behaviour should be based on a set of various internal and external factors, take into account both the effect of innovative work (including income) and the dynamism of staff needs, which are not limited to wages and continue significantly will depend on the opportunities and conditions of creative self-realization at work, recognition of creative achievements, continuous professional development.

\section{Conclusions}

In the context of global transformations, the prospects for improving innovation management in Ukraine largely depend on the restructuring of motivational management, in particular the search for an acceptable motivational mechanism that can provide priority stimulation of creative content, which depends on the development of new ideas. Solving this problem, in turn, requires radical changes in the motivation of employees to innovate. It is substantiated that under the influence of innovative changes in economy, employment, content of work in science the process of overcoming the limitations of traditional views on the labor process continues, scientific thought about work and its components is enriched, views on motivation as a driving force of labor behaviour in innovation, its role in intensifying innovative work. The study of the advantages of creative, innovative work over regulated (reproductive) work allowed based on modelling to identify features that should be taken into account by motivational management, in particular: dependence of innovative enterprise income on stimulating creative work, different reaction of employees to different incentives and labor availability and magnitude of the positive effect. By modelling and involving expert assessments of the effectiveness of innovative work in 14 surveyed enterprises, it was proved that the choice of motivational priorities in regulating creativity and innovative activity of staff should be in favor of stimulating the creative component of work. In the interests of improving innovation management, the concept of forming a motivational mechanism for providing priority stimulation of creative content is proposed and a corresponding scheme of the mechanism is developed. The scheme stipulates that the evaluation of work results should take into account the regulated and creative (innovative) components of labor and, accordingly, flexibly affect the employee's income. Depending on this assessment, as well as the importance of the employee's contribution to the development of innovations, the effect obtained, he should be offered significant economic, social and moral and psychological incentives. The joint implementation of the regulated and creative component of labor in the labor process is proposed to be considered as stimulating: regulated - the basic salary, creative - additional; the reward for creativity is an individualized set of economic, social and moralpsychological incentives, formed taking into account the results of motivational monitoring.

The scientific validity of the proposed approach to the motivational regulation of innovative activity of employees, the flexibility of the motivational mechanism and the possibility of adjusting its action depending on the effectiveness of innovative work, the state of internal and external environment, allow to recommend this development for practical use in innovative enterprises. 


\section{References}

1. Barbaroux, P., Attour, A., \& Schenk, E. (2016). Managing Knowledge to Innovate: Open and Distributed Innovation Models. Knowledge Management and Innovation: Interaction, Collaboration, Openness, 6.

2. Bell, A., Chetty, R., Jaravel, X., Petkova, N., \& Van Reenen, J. (2019). Who Becomes an Inventor in America? The Importance of Exposure to Innovation, The Quarterly Journal of Economics, May, 134(2), 2019, 647-713.

3. Hollen, R. M., Van Den Bosch, F. A., \& Volberda, H. W. (2013). The Role of Management Innovation in Enabling Technological Process Innovation. European Management Review, 10(1), 35-50.

4. Human development in Ukraine. Innovative types of employment and prospects for their development (2016). Edited by E. Libanova. Ptoukha Institute for Demography and Social Studies of the NAS of Ukraine. Kyiv. https://www.idss.org.ua/monografii/2017_lud_rozvytok.pdf

5. Khan, M. J., Aslam, N., \& Riaz, M. N. (2012). Leadership styles as predictors of innovative work behavior. Pakistan Journal of Social \& Clinical Psychology, 9(2).

6. Kim, H. K., Baik, K., \& Kim, N. (2019). How Korean Leadership Style Cultivates Employees' Creativity and Voice in Hierarchical Organizations. SAGE Open, 9(3).

7. Kolot, A. (2007) Innovative labor and intellectual capital in the system of factors forming the knowledge economy. Ukraine: aspects of labor, 4, 4-9.

8. Lee, H. W., Pak, J., Kim, S., \& Li, L. Z. (2016). Effects of Human Resource Management Systems on Employee Proactivity and Group Innovation. Journal of Management, December, 45(2), 819-846.

9. Lisogor, L. (2016). Formation of innovative employment in the conditions of modernization of economy and transformation of social relations. Economics and organization of management. Collection of scientific works. Vinnytsia: DonNU, 3(23), 82-90.

10. Makarova, O. (2015). Measurement of human development in the regions of Ukraine: methodological aspects and evaluation of results. Economy of Ukraine, 3, 41-53.

11. Maurer, T. J., \& London, M. (2015). From Individual Contributor to Leader: A Role Identity Shift Framework for Leader Development Within Innovative Organizations. Journal of Management, 44(4), 1426-1452.

12. Naujokaitiene, J., Tereseviciene, M., \& Zydziunaite, V. (2015). Organizational Support for Employee Engagement in Technology-Enhanced Learning. SAGE Open, 5(4).

13. Pisarenko, T., Kvasha, T., Rozhkova, L., \& Kovalenko, O. (2020). Innovative activity in Ukraine in 2019 scientific and analytical report. K.: UkrINTEI. https://mon.gov.ua/storage/app/media/innovatsii-transfer-tehnologiy/2020/08/za-2019-11.pdf

14. Schiavone, F. (2021). User - User Innovation: Interactions Between Users and Firms in Innovation Processes. Innovation Economics, Engineering and Management Handbook 1: Main Themes.

15. Semykina M., \& Paseka S. (2012) Innovative work: diagnostics of problems, levers of activation. Cherkasy: MACLAUT LLC.

16. Volberda, H. W., Van Den Bosch, F. A. J, \& Heij, C. V. (2013). Management Innovation: Management as Fertile Ground for Innovation. European Management Review, 10(1), 1-15. 